\title{
WAsP model performance verification using lidar data
}

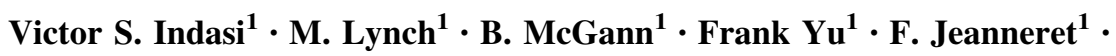 \\ J. Sutton ${ }^{1}$
}

Received: 27 March 2015 / Accepted: 21 August 2015/Published online: 6 November 2015

(C) The Author(s) 2015. This article is published with open access at Springerlink.com

\begin{abstract}
This study describes the verification of Wind Atlas Analysis and Application program (WAsP) modelled average wind speeds in a complex terrain. WAsP model was run using data collected at 3 masts: Kalkumpei, Nyiru and Sirima using cup anemometers and wind vanes for the entire 2009 calendar year and verified using data collected by WindTracer LIDAR (light detection and ranging) for 2 weeks from 11th to 24th July 2009. Evaluating WAsP mean wind speed map using LIDAR data showed that Nyiru station provides the best data to model mean wind speed over the wind farm domain with a mean difference of $0.16 \mathrm{~m} / \mathrm{s}$, root mean square error of $0.85 \mathrm{~m} / \mathrm{s}$ and Index of Agreement of 0.61. Construction of a $310 \mathrm{MW}$ windfarm has commenced at this site. Once completed, the windfarm will be operating 365 vestas V52-850kW turbines.
\end{abstract}

Keywords WAsP · LIDAR - Complex terrain · Wind resource assessment

\section{Introduction}

WAsP is the wind energy industry standard model used to assess the mean wind speed and energy output at a specific site or at a high resolution over a wider area. WAsP, whose sub-models were first developed by the Ris $\varnothing$ National Laboratory in 1987, is commonly used throughout the world in the wind energy industry to get an estimate of available regional wind resources, to site turbines at

Victor S. Indasi

v.indasi@postgrad.curtin.edu.au

1 Department of Physics and Astronomy, Curtin University, Bentley, WA, Australia specific locations, and to estimate wind farm production [1].

WAsP is based on physical principles of flows in the boundary layer and attempts to solve the Navier-Stokes momentum equations, estimates the regional wind climate, as well as the wind speed at any specific location and height. This is done by horizontally and vertically extrapolating a record of wind data within the region using steps that take into consideration elevation or topography changes, land use or classification/surface roughness, and local obstacles [2].

WAsP has been applied to a wide variety of situations including flat, open terrain [3]; offshore locations [4, 5]; coastal locations [6]; mountainous terrain; [7]; forested terrain [8]; extreme winds $[9,10]$ and short-range weather forecasting [11].

Barthelmie et al. [4] found that for offshore locations WAsP tended to over-predict the mean speed. The differences were thought to be due to the incorrect assignment of roughness lengths and stability effects.

Romeo and Magri [6] found that WAsP produced good estimates of the mean speed for a coastal site in southeast Sicily. They used data from a numerical model as the starting point for the analysis.

Suárez et al. [8] studied an area of mountainous, forested terrain in western Scotland. Using an anemometer on an exposed ridge as their reference site, they found that WAsP produced an accurate estimate of the mean speed at another nearby hill-top site $(7.5 \mathrm{~km}$ to the east southeast). However, for two valley locations in the same area, the mean speed was underestimated by around $15 \%$, and for a site in a saddle and a site on the side of a valley the WAsP estimates were too high by $15-20 \%$.

Landberg and Mortensen [11] compared WAsP and Measure-Correlate-Predict (MCP) using data from six complex terrain stations in northern Portugal. They 
demonstrated that WAsP will produce poor results if the reference and target site are in different climatic zones.

Onat and Ersoz [12] used five-layer sugeno-type model scripted in MATLAB and WAsP to describe the characteristics of wind climate and energy potential for three regions in Turkey. Their analysis produced detailed wind resource maps and concluded that the regions are well located for the installation of parallel-connected wind plants to the national network in terms of the reliability of wind and capacity usage rates.

Palaiologou et al. [13] used GIS and WAsP as basic calculation platforms to test and evaluate measurements from 15 wind turbine sites by creating six alternative scenarios in the island of Lesvos, Greece. They demonstrated that topography plays a critical role in the accuracy of WAsP calculations.

Djamai and Merzouk [14] used WAsP to investigate the possibility of setting up a $10 \mathrm{MW}$ wind farm in Adrar, a region located in the south of the country. Lima and Filho [15] conducted a wind resource evaluation and wind energy assessment for São João do Cariri in Paraiba state of northeast. They both demonstrated that WAsP program is a robust and reliable tool to make wind characterization and wind energy potential assessment.

The predictions from WAsP for wind flows over simple isolated hills compare well with the measured data from the two benchmark field measurements [16]. Additional independent assessments of WAsP for more complex terrain situations, which lie largely within its operating envelope, generally confirm the reliability of the predictions under these conditions.

There are several factors which influence the accuracy of a power estimates using WAsP. These factors are broadly classified into four categories: Atmospheric conditions [17, 18], Orography [19], Weibull fit error and wind data records [18].

Due to some of the simplifications made in the numerical models used within WAsP, the program can produce somewhat inaccurate results when used outside its recommended operational envelope [18]. When a site has complex, rugged terrain or very complex atmospheric conditions, the accuracy of WAsP can be unreliable [18].

This problem can be solved using several reference sites and cross-referencing sites where wind observations are available. There is also the option for some user corrections at problematic sites which can significantly improve the accuracy of the model in complex terrain [20].

The aim of this study was to evaluate the accuracy of the WAsP model using high spatial resolution LIDAR data. To achieve this, WAsP was run using wind data from 3 instrumented meteorological masts; the resulting mean wind speeds were compared to mean wind speed retrieved from LIDAR.

\section{Area of study}

The region of study is north-western Kenya where the winds are generated by a low-level jet called the Turkana easterly low-level jet. The jet stream is created by the much bigger East African low-level jet. The Turkana Channel jet blows lasting through the year from the South East through the valley between the East African and the Ethiopian Highlands extending from the Ocean to the deserts in Sudan [21]. The wind is enhanced locally between Mt. Kulal (2300 m ASL) and the Mt Nyiru Range (2750 m ASL). Both Kinuthia and Asnani [21, 22] observed that, throughout the year, the NE and SE monsoon near the equator branches off from the Indian Ocean, enters the Turkana channel and intensifies (Fig. 1). They further hypothesized that the configuration of the Ethiopian highlands and the East African highlands could be playing a critical role in the development and maintenance of the Turkana low-level jet through the orographic channelling effect.

\section{WAsP model set-up}

The analysis procedure of WAsP program was used to generate a wind atlas files based on wind observations from 3 meteorological mast locations located in North-western Kenya. These locations fall in Universal Transverse Mercator (UTM) zone 37; their coordinates and measurement heights are given in Table 1 . These masts are equipped with cup anemometers and wind vanes which recorded wind data for a whole calendar year, 2009.

The observed data at the 3 masts were analysed to generate observed wind climate. Observed wind climate represents as closely as possible the long-term wind climate at anemometer height at the position of the meteorological mast. In case no MCP is carried out, one may only hope that the particular year (of the dataset) is representative for the long-term wind climate. The observed wind climate was then combined with terrain data from Shuttle Radar Topography Mission (SRTM) to generate local wind atlas. The maps are based on $45 \mathrm{~m}$ above ground mean wind speed and Annual Energy Production (AEP) calculations at $100 \mathrm{~m}$ resolution. AEP calculations were based on a Vestas V52 turbine.

Vestas turbines have established themselves as a premier brand within the wind energy industry. The vestas V52-850kW turbines have a rotor diameter of 52 metres and have a hub height of 45 metres at this particular wind farm. It has a nominal output of $850 \mathrm{~kW}$. It has cut-in wind speed of $4 \mathrm{~m} / \mathrm{s}$, a cut-out wind speed of $25 \mathrm{~m} / \mathrm{s}$. At $16 \mathrm{~m} / \mathrm{s}$, it reaches its maximum output. 

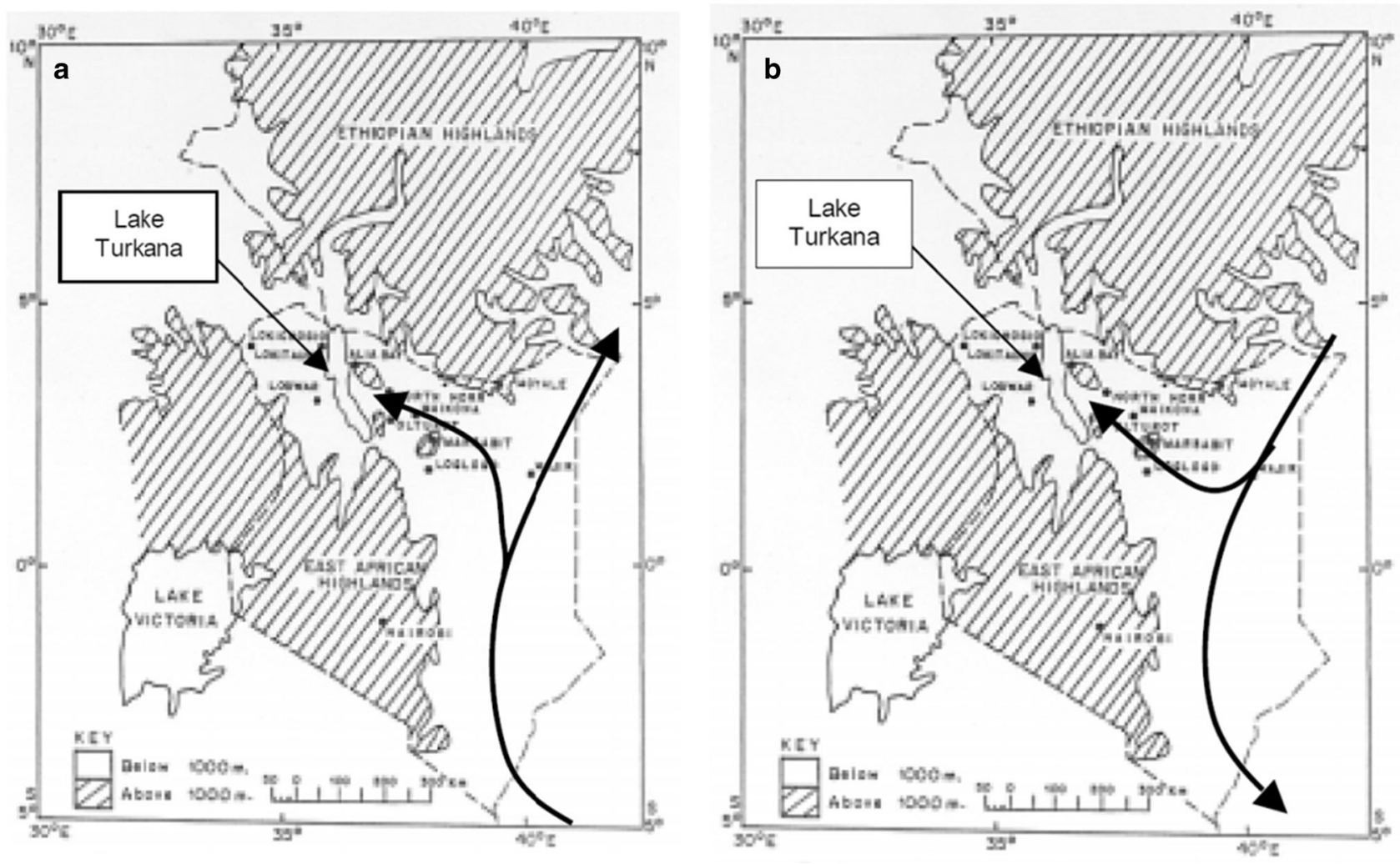

Fig. 1 A simplified model showing the cross-equatorial monsoon flow diverting into the Turkana channel during a northern summer, and b northern winter [23]

Table 1 Details about the meteorological mast locations

\begin{tabular}{llllll}
\hline Site name & Easting & Northing & Height ASL $(\mathrm{m})$ & Anemometer height $(\mathrm{m})$ & Wind vane height $(\mathrm{m})$ \\
\hline Kalkumpei & 261707 & 279998 & 804 & 38.5 & 39 \\
Nyiru & 255724 & 272182 & 872 & 46 & 49 \\
Sirima & 259589 & 273686 & 832 & 38 & 40 \\
\hline
\end{tabular}

WAsP uses Weibull distributions to represent the sectorwise wind speed distributions and the emergent distribution for the total (Omni-directional) distribution. The difference between the fitted (and emergent) and the observed wind speed distributions should therefore be small: less than about $1 \%$ for mean power density (which is used for the Weibull fitting) and less than a few per cent for mean wind speed [24]. If wind speed has been measured at two or more heights along the mast, the top anemometer is almost always used as the reference level [24].

The analysis and prediction of the regional wind climate was calculated by considering 5 reference roughness lengths $(0.000,0.020,0.100,0.400,1.000 \mathrm{~m})$ and 5 reference heights $(20,40,45,70,90 \mathrm{~m})$ above ground level. Roughness length of $0.0 \mathrm{~m}$ is recommended by WAsP for water bodies like Lake Turkana which is to the west of the wind farm. The roses of Weibull parameters have $12 \mathrm{sec}-$ tors each. The wind farm area defined by the boundary $[(248950,265950)$ to $(262050,286050)]$ was divided into rows and columns measuring $100 \mathrm{~m}$ in length and width. Multiplying 131 columns and 201 rows gives the 26331 calculations sites. The grid set used is given below.

\begin{tabular}{ll}
\hline Structure: & $\begin{array}{c}\text { 131 columns and 201 rows at } 100 \mathrm{~m} \\
\text { resolution gives 26,331 calculation sites }\end{array}$ \\
Boundary: & $(248950,265950)$ to $(262050,286050)$ \\
Nodes: & $(249000,266000)$ to $(262000,286000)$ \\
Height a.g.l.: & $45 \mathrm{~m}$ \\
Wind turbine generator: & Vestas V52-850 kW
\end{tabular}




\section{Results}

Results were obtained for mean wind speed, power density, annual energy production and Ruggedness Index (RIX). RIX is an orographic performance indicator measured as a fraction of the surrounding terrain that exceeds a slope of 0.3 [18]. However, only mean wind speed maps are presented since it is the only item that was verified using LIDAR data.
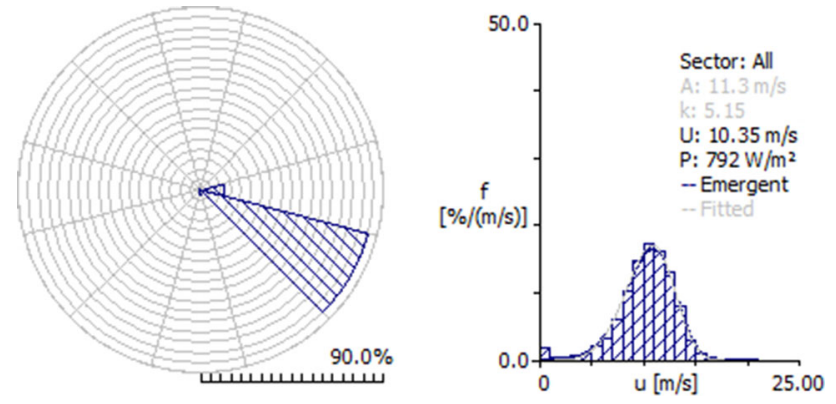

Fig. 2 Wind Rose for the annual data collected at Kalkumpei mast and wind speed distribution (Weibull) for all sectors (wind directions) from WAsP

\section{Kalkumpei: regional wind climate summary}

\section{Mean speed}

Figure 2 below shows the wind speed resource map at $45 \mathrm{~m}$ hub height, the first figure with contour lines together with proposed turbine locations and the second is without contour lines. The wind speed ranges from a minimum of $5.36 \mathrm{~m} / \mathrm{s}$, represented by the blue colour on the map, to a maximum value of $16.55 \mathrm{~m} / \mathrm{s}$ represented by the red colour. The mean wind speed is $10.72 \mathrm{~m} / \mathrm{s}$, according to the WASP 11 Wind Atlas Calculations (Fig. 3).

\section{Nyiru: regional wind climate summary}

\section{Mean speed}

Figure 4 below shows the wind speed resource map at $45 \mathrm{~m}$ hub height, the first figure with contour lines together with proposed turbine locations and the second is without contour lines. The wind speed ranges from a minimum of $5.10 \mathrm{~m} / \mathrm{s}$, represented by the blue colour on the map, to a
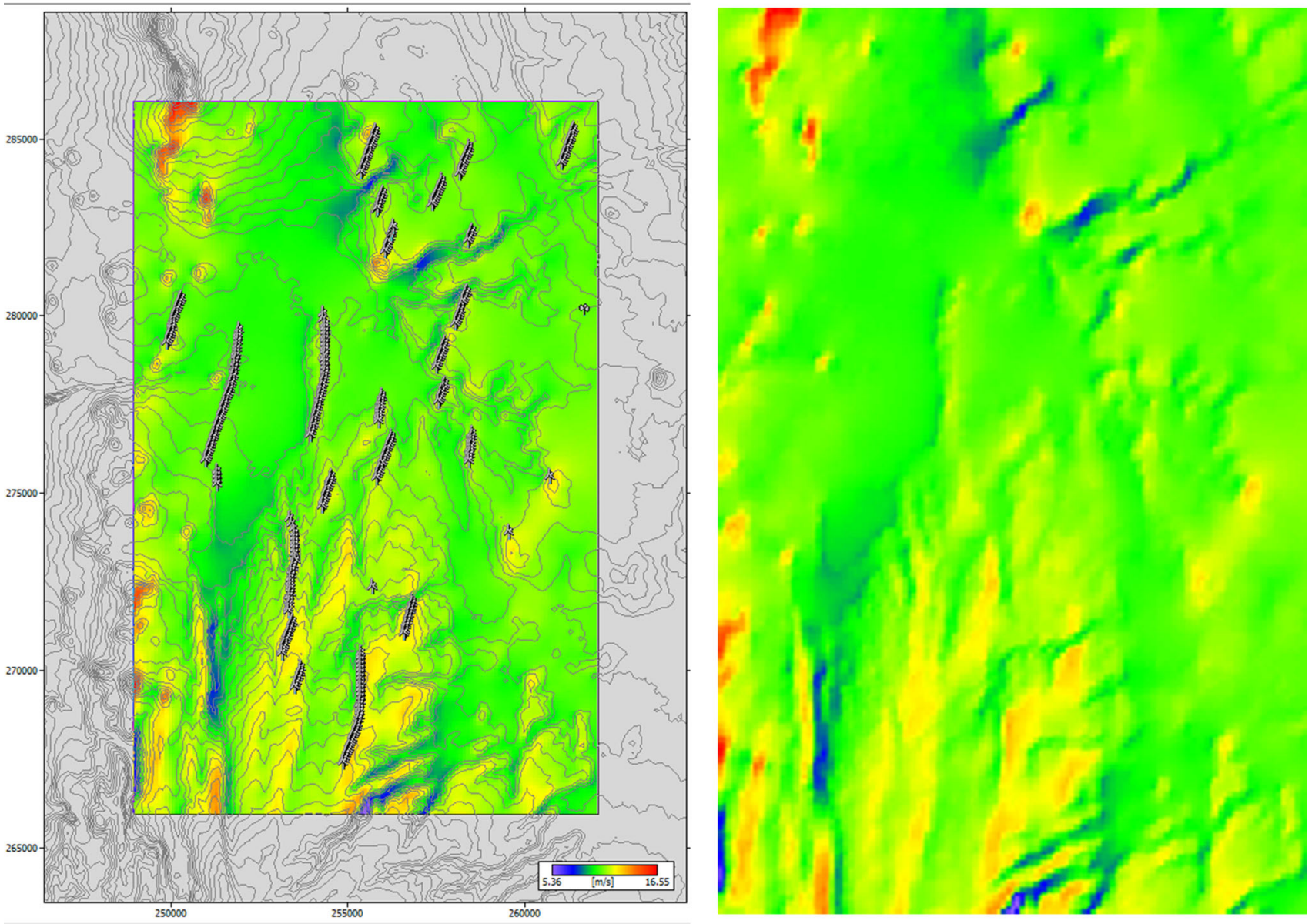

Fig. 3 Wind speed Resource Map at $45 \mathrm{~m}$ wind turbine height using Kalkumpei mast data 

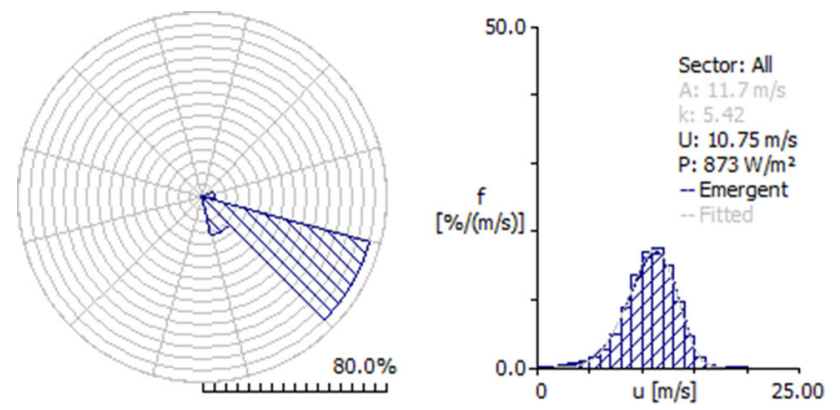

Fig. 4 Wind Rose for the annual data collected at Nyiru mast and wind speed distribution (Weibull) for all sectors (wind directions) from WAsP

maximum value of $15.75 \mathrm{~m} / \mathrm{s}$ represented by the red colour. The mean wind speed is $10.16 \mathrm{~m} / \mathrm{s}$, according to the WASP 11 Wind Atlas Calculations (Fig. 5).

\section{Sirima: regional wind climate summary}

\section{Mean speed}

Figure 6 below shows the wind speed resource map at $45 \mathrm{~m}$ hub height, the first figure with contour lines together with proposed turbine locations and the second is without contour lines. The wind speed ranges from a minimum of $5.93 \mathrm{~m} / \mathrm{s}$, represented by the blue colour on the map, to a maximum value of $16.20 \mathrm{~m} / \mathrm{s}$ represented by the red colour. The mean wind speed is $10.19 \mathrm{~m} / \mathrm{s}$, according to the WASP 11 Wind Atlas Calculations.

\section{Accuracy of WAsP predictions}

Predictions of the mean wind speeds for three sites by WAsP V11 are presented in Table 5. Note that the values presented in Table 5 are WAsP predictions after factoring
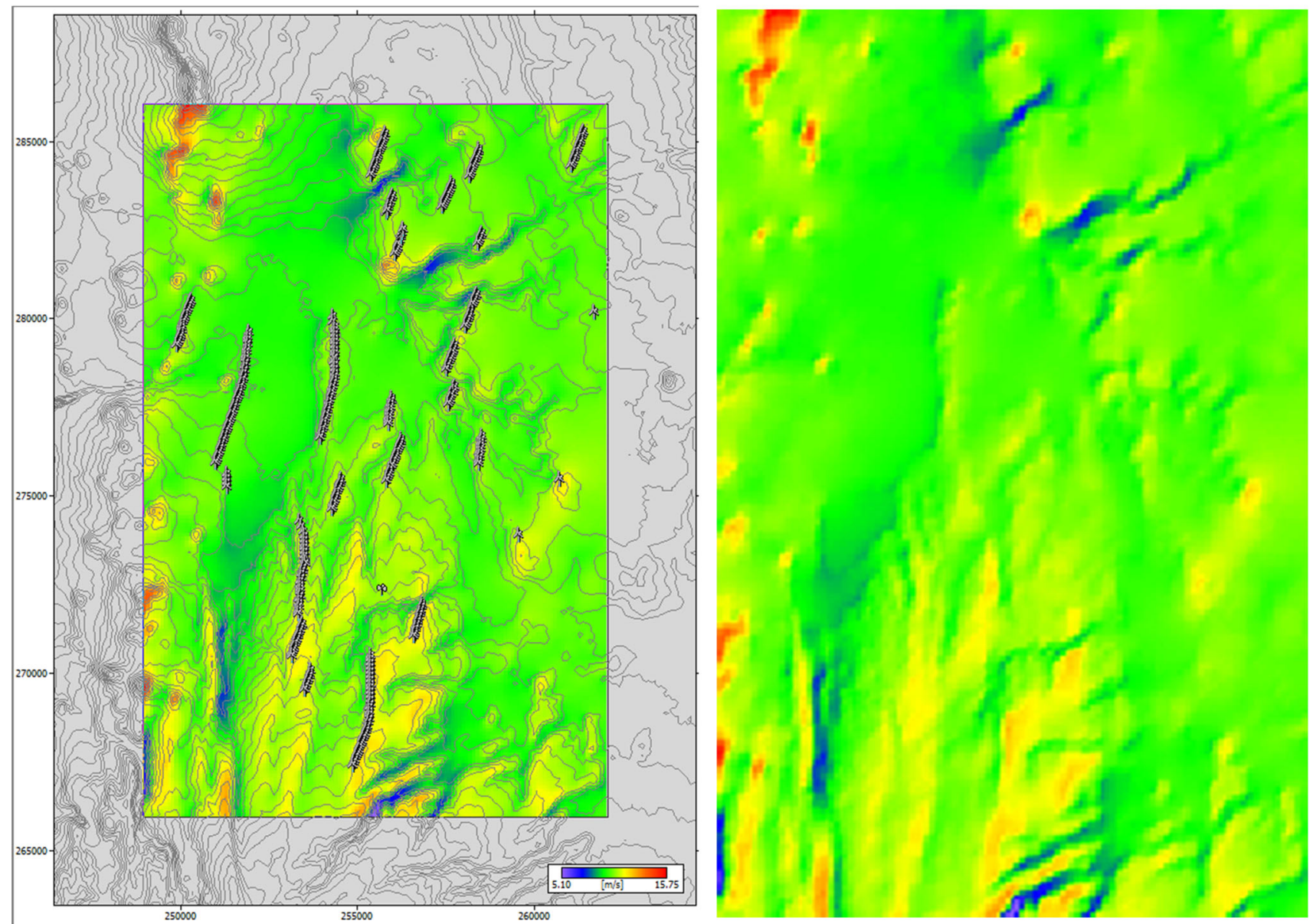

Fig. 5 Wind speed Resource Map at $45 \mathrm{~m}$ wind turbine height using Nyiru mast data 

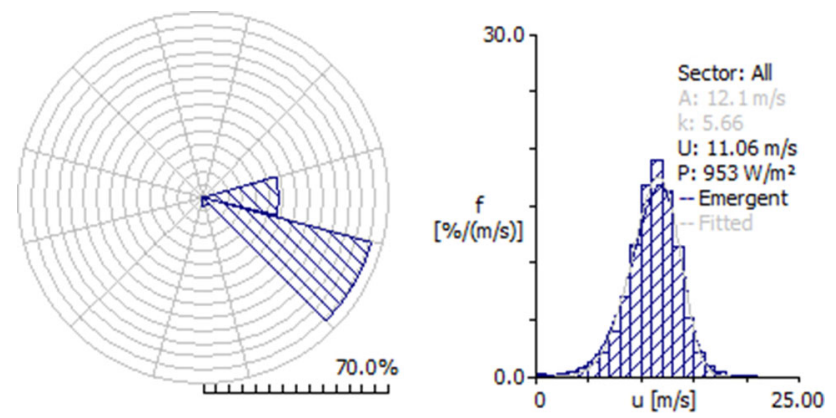

Fig. 6 Wind Rose for the annual data collected at Sirima mast and wind speed distribution (Weibull) for all sectors (wind directions) from WAsP

Table 2 Results from the observed wind climate in WAsP

\begin{tabular}{llll}
\hline Parameter & Measured & Emergent & Discrepancy \\
\hline Mean wind speed $(\mathrm{m} / \mathrm{s})$ & 10.25 & 10.35 & $1.0 \%$ \\
Mean power density $\left(\mathrm{W} / \mathrm{m}^{2}\right)$ & 792 & 792 & $0.1 \%$
\end{tabular}

The emergent wind speeds are the weighted sums of the Weibull distributions in all directions

Table 3 Results from the observed wind climate in WAsP

\begin{tabular}{llll}
\hline Parameter & Measured & Emergent & Discrepancy \\
\hline Mean wind speed $(\mathrm{m} / \mathrm{s})$ & 10.75 & 10.75 & $0.0 \%$ \\
Mean power density $\left(\mathrm{W} / \mathrm{m}^{2}\right)$ & 871 & 873 & $0.2 \%$
\end{tabular}

The emergent wind speeds are the weighted sums of the Weibull distributions in all directions

in topography, while values in Tables 2,3 and 4 are observed mean wind speeds.

Similar predictions were reported by [18] using WAsP V11. The errors vary in sign and are sometimes large. However, good predictions are obtained for site pair combinations involving Nyiru and Sirima mast locations, including all the self-prediction cases.

\section{Evaluating mean wind speed maps using LIDAR data}

WindTracer LIDAR was deployed at the site between 11th July and 25th July 2009 to record wind data. Advanced LIDAR data volume processing technique (ALVPT) developed by a research group based in Perth, Western Australia was used to process raw LIDAR data to get wind speed and direction time series datasets [25].

\section{ALVPT algorithm}

The direct measurements of wind by LIDAR are restricted to the radial component of the wind. To resolve the
Table 4 Results from the observed wind climate in WAsP

\begin{tabular}{llll}
\hline Parameter & Measured & Emergent & Discrepancy \\
\hline Mean wind speed $(\mathrm{m} / \mathrm{s})$ & 11.10 & 11.06 & $-0.4 \%$ \\
Mean power density $\left(\mathrm{W} / \mathrm{m}^{2}\right)$ & 952 & 953 & $0.2 \%$ \\
\hline
\end{tabular}

The emergent wind speeds are the weighted sums of the Weibull distributions in all directions

Table 5 Score tables for predictions at site using 3 masts

\begin{tabular}{llrrl}
\hline Site & Kalkumpei & Nyiru & Sirima & Measured \\
\hline Mean wind speeds & & & & \\
Kalkumpei (m/s) & 10.65 & 9.82 & 9.73 & 10.25 \\
Nyiru (m/s) & 11.29 & 10.69 & 10.65 & 10.75 \\
Sirima (m/s) & 11.64 & 11.00 & 11.24 & 11.10 \\
Percentage differences between predicted and measured wind speeds \\
Kalkumpei (m/s) & -3.90 & 4.19 & 5.07 & 0 \\
Nyiru (m/s) & -5.02 & 0.55 & 0.93 & 0 \\
Sirima (m/s) & -4.86 & 0.90 & -1.26 & 0 \\
\hline
\end{tabular}

Top row contains the reference sites, left-hand column the predicted sites

tangential components of the wind, LIDAR beam measurements of the radial component are used from other directions. By taking adjacent or lateral radial velocity measurements at defined range gates, the ALVPT algorithm is then used to estimate wind vectors that exemplifies the localized mean wind at the specified range gate location.

The ALVPT algorithm first clusters the obtained LIDAR data from the volume of sweeps into small conical analysis volumes. Each of these volumes utilizes 10-20 radial velocity data points, contingent up on the size of the conical analysis volume. As more radial velocity data points are included in the analysis volume, the larger the analysis volume needs to be. This would mean a reduction in the retrieved wind field resolution. On the other hand, with less radial velocity data points, the retrieval of the wind becomes ill-conditioned and computationally unstable, which leads to errors in the retrieved wind field. It is therefore important to understand the trade-off between these two factors to produce a quality-controlled retrieval. For the given unit analysis volume, the VVP algorithm automatically loops through all analysis volumes, applying a least squares minimization scheme to obtain solutions.

Once the solutions are obtained, a quality check is performed to filter out solutions that are not considered to be reasonable. The solutions retrieved are then registered at the centre of each analysis volume and further gridded to a rectangular mesh of $150 \mathrm{~m} \times 150 \mathrm{~m}$ resolution. 

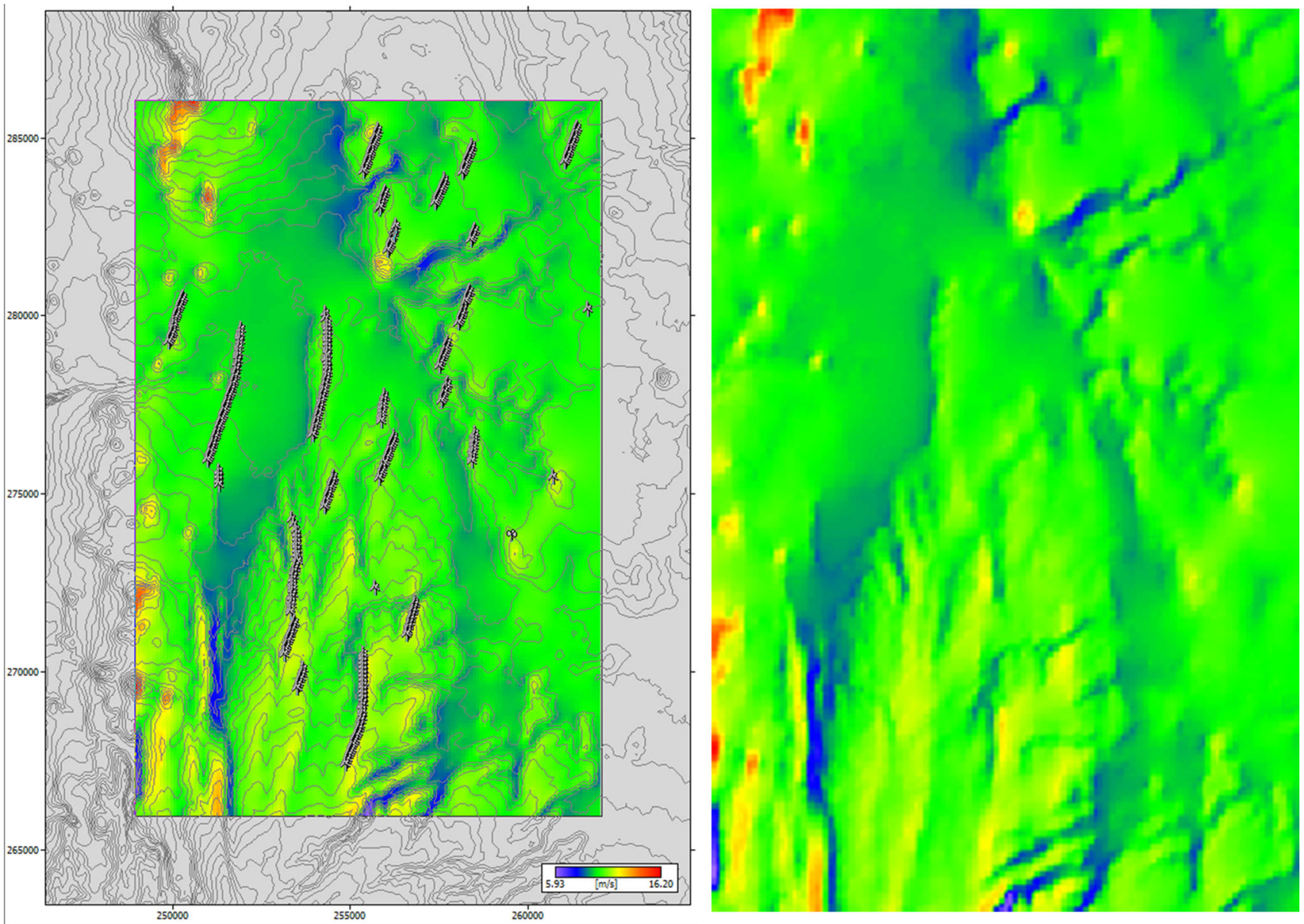

Fig. 7 Wind speed Resource Map at $45 \mathrm{~m}$ wind turbine height using Sirima mast data

\section{WAsP mean wind speed validation}

An experiment was designed to use high-resolution spatial LIDAR data to validate WAsP mean wind speed maps. WAsP was run for 15 days between 11th and 24th July 2009. Using the LIDAR data, 1139 virtual masts were designed within Lake Turkana wind farm. These virtual masts were then used to validate WAsP mean wind speed maps. Figure 7 below shows the wind farm domain with the virtual mast locations. The location of the LIDAR is: 260743.2 Easting and 275307.7Northing within UTM zone 37 (Fig. 8).

The results for this evaluation exercise of WAsP mean wind speed map are given below.

Evaluating WAsP mean wind speed map using LIDAR data shows that Nyiru station provides the best data to model mean wind speed over the wind farm domain with a mean difference of $0.16 \mathrm{~m} / \mathrm{s}$, RMSE of $0.85 \mathrm{~m} / \mathrm{s}$ and IOA of 0.61 (Table 6). Table 4 shows results from cross prediction using mast observed data. The results presented in this table also indicate that observed data at Nyiru mast provide the best dataset for micro-scale modelling using WAsP.

\section{Conclusion}

WAsP provides slightly different wind atlas maps when datasets from different masts or sources are used. The mean wind speed over the wind farm domain was $10.72 \mathrm{~m} / \mathrm{s}$, $10.16 \mathrm{~m} / \mathrm{s}$ and $10.19 \mathrm{~m} / \mathrm{s}$ when observed data at Kalkumpei, Nyiru and Sirima were used, respectively. Cross and self-prediction results indicate that Nyiru dataset was the most appropriate for WAsP modelling at this study site.

The wind speed derived from Doppler LIDAR data was output into a $20 \mathrm{~km}$ by $20 \mathrm{~km}$ grid domain and overlaid on 
Fig. 8 Location of the virtual masts and position of LIDAR (circled in blue)

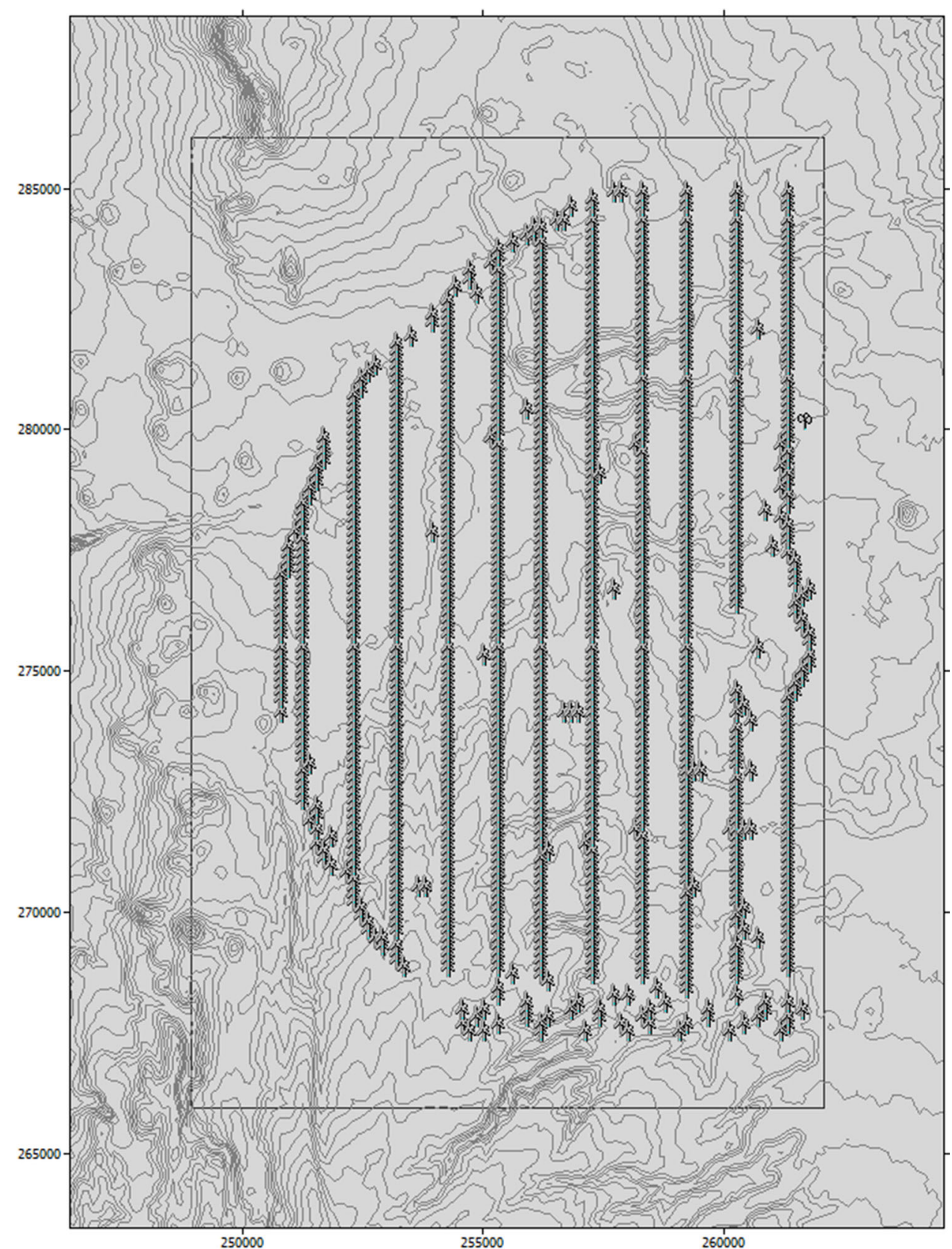

a digital terrain model to create a wind atlas map. This data provide a useful product for evaluating WAsP predictions over a wind farm domain. This was achieved by creating virtual masts from the LIDAR data and comparing with data from WAsP model. Evaluating WAsP mean wind speed map using LIDAR shows that Nyiru station provides the best data for WAsP modelling over Lake Turkana wind farm domain with a mean difference of $0.16 \mathrm{~m} / \mathrm{s}$, RMSE of $0.85 \mathrm{~m} / \mathrm{s}$ and IOA of 0.61 .

LIDAR being mobile has shown great potential to assess winds accurately at any particular site for a range of heights over an area of $\sim 200 \mathrm{~km}^{2}$ and with high radial resolution $(\sim 150 \mathrm{~m})$. Use of Doppler LIDAR for wind assessment is still maturing. Equipment configuration and software 
Table 6 Error statistics between wind speed data generated by WAsP using observed data and LIDAR data

\begin{tabular}{lr}
\hline$M E$ & -0.33 \\
LIDAR-WAsP (using Kalkumpei mast data) (m/s) & 0.16 \\
LIDAR-WAsP (Using Nyiru mast data) (m/s) & 0.63 \\
LIDAR-WAsP (Using Sirima mast data) (m/s) & 1.06 \\
$R M S E$ & 0.85 \\
LIDAR-WAsP (Using Kalkumpei mast data) (m/s) & 1.09 \\
LIDAR-WAsP (Using Nyiru mast data) (m/s) & \\
LIDAR-WAsP (Using Sirima mast data) (m/s) & 0.46 \\
IOA & 0.6 \\
LIDAR-WAsP (Using Kalkumpei mast data) & 0.53 \\
LIDAR-WAsP (Using Nyiru mast data) & \\
LIDAR-WAsP (Using Sirima mast data) & \\
\hline
\end{tabular}

The first table contains mean error (ME) results, the second contains root mean square error (RMSE) results and the last contains Index of Agreement (IOA) results

changes especially the ALVPT may affect measurement quality and accuracy of retrieved wind speed and direction.

Acknowledgments This work was funded by Cooperative Research Centre for Contamination Assessment and Remediation of the Environment (CRC CARE). Many thanks to Technical University of Denmark, Department of Wind Energy for providing us with a free WAsP academic license.

Open Access This article is distributed under the terms of the Creative Commons Attribution 4.0 International License (http://crea tivecommons.org/licenses/by/4.0/), which permits unrestricted use, distribution, and reproduction in any medium, provided you give appropriate credit to the original author(s) and the source, provide a link to the Creative Commons license, and indicate if changes were made.

\section{References}

1. Mortensen, N.G.: Getting started with WAsP 9. Ris $\varnothing-\mathrm{I}-2571$ (EN). Risoe National Laboratory, Technical University of Denmark, Roskilde (2007)

2. Troen, I., Lundtang Petersen, E.: European wind atlas (1989)

3. Achberger, C., Ekström, M., Bärring, L.: Estimation of local near-surface wind conditions-a comparison of WASP and regression based techniques. Meteorol. Appl. 9, 211-221 (2002)

4. Barthelmie, R.J., Courtney, M.S., Højstrup, J., Larsen, Søren Ejling: Meteorological aspects of offshore wind energy: observations from the Vindeby wind farm. J. Wind Eng. Ind. Aerodyn. 62, 191-211 (1996)
5. Lange, Bernhard, Højstrup, Jørgen: Evaluation of the wind-resource estimation program WAsP for offshore applications. J. Wind Eng. Ind. Aerodyn. 89, 271-291 (2001)

6. Romeo, R., Magri, S.: Wind energy evaluation for breakwater plants. Wind Eng. 18, 199-206 (1994)

7. Reid, S.: Modelling of channelled winds in high wind areas of New Zealand. Weather Clim. 17, 3-22 (1997)

8. Suárez, Juan C., Gardiner, Barry A., Quine, Christopher P.: A comparison of three methods for predicting wind speeds in complex forested terrain. Meteorol. Appl. 6, 329-342 (1999)

9. Abild, J.: Application of the wind atlas method to extremes of wind climatology (1994)

10. Kristensen, Leif, Rathmann, O., Hansen, S.O.: Extreme winds in Denmark. J. Wind Eng. Ind. Aerodyn. 87, 147-166 (2000)

11. Landberg, L., Mortensen, N.G.: A comparison of physical and statistical methods for estimating the wind resource at a site. In: 15th British Wind Energy Association Conference (1993)

12. Onat, N., Ersoz, S.: Analysis of wind climate and wind energy potential of regions in Turkey. Energy 36, 148-156 (2011)

13. Palaiologou, P., Kalabokidis, K., Haralambopoulos, D., Feidas, H., Polatidis, H.: Wind characteristics and mapping for power production in the Island of Lesvos, Greece. Comput. Geosci. 37, 962-972 (2011)

14. Djamai, M., Merzouk, N.K.: Wind farm feasibility study and site selection in Adrar, Algeria. Energy Proc. 6, 136-142 (2011)

15. Lima, L.A., Filho, C.R.B.: Wind resource evaluation in São João does Cariri (SJC)—Paraiba, Brazil. Renew. Sustain. Energy Rev. 16, 474-480 (2012)

16. Troen, I.: A high resolution spectral model for flow in complex terrain. In: 9th symposium on turbulence and diffusion (1990)

17. Bowen Anthony, J., Mortensen, N.G.: Exploring the limits of WAsP-the wind atlas analysis and application program. Risocontribution from the Department of Meteorology and Wind Energy to the EUWEC (1996)

18. Bowen, A.J., Mortensen, N.G.: WAsP prediction errors due to site orography (2004)

19. Frank, H.P., Rathmann, O., Mortensen, N.J., Landberg, L.: The numerical wind atlas-the KAMM/WAsP method. Riso Tech. Rep. Riso-R-1252(EN) (2001)

20. Wagner, R., Antoniou, I., Pedersen, S.M., Courtney, M.S., Jørgensen, H.E.: The influence of the wind speed profile on wind turbine performance measurements. Wind Energy 12, 348-362 (2009)

21. Kinuthia, J.H., Asnani, G.C.: A newly found jet in North Kenya (Turkana Channel). Mon. Weather Rev. 110, 1722-1728 (1982)

22. Kinuthia, J.H.: Horizontal and vertical structure of the Lake Turkana jet. J. Appl. Meteorol. 31, 1248-1274 (1992)

23. Indeje, M.: Predictions and numerical simulations of the regional climate of equatorial eastern Africa. PhD, North Carolina State University (2000)

24. Mortensen, N.G.: Planning and development of wind farms: wind resource assessment and siting. Danmarks Tekniske Universitet, Risø Nationallaboratoriet for Bæredygtig Energi (2012)

25. CRC-CARE: Lake Turkana LIDAR wind field assessment. CRCCARE, Perth (2011) 